\title{
Help Farmers - Farm Era App
}

\author{
Mrs.D.Thamizhselvi a,1, Ms.S.V.Supraja ${ }^{\text {a }}$ and Ms.G.Priyadharshini ${ }^{\text {a }}$ \\ ${ }^{a}$ Dept of IT, Sri Sairam Engineering College, Chennai, Tamilnadu, India.
}

\begin{abstract}
The income of the famers has decreased drastically over the past years as they do not have the proper channel for marketing their produce. This has also proved to be the factor that favors the landlords and money lenders to gain possession over their agricultural products at a very low cost and obtain a large profit from it. This also reflects the inability of farmers to obtain the righteous profit from their produce. The main aim of our project is to organizing and uniting the farmers under one umbrella, to reduce the unbalanced accumulation of the profit from perishable farm produces for the traders and the sellers and help maximise the income level of the farmers by self-marketing. This system has been implemented by considering the entire supply-demand eco system and it also helps avoid product wastage.
\end{abstract}

Keywords. Marketing, Direct Selling, Direct Marketing, E-business, E-commerce, Self-Marketing.

\section{Introduction}

Food wastage is a major problem in India. It is estimated that around Rs 58,000 crores worth of food is wasted each year during production, processing, retailing and consumption. About $25-30 \%$ of the fruits and vegetables produced are wasted due to poor logistical support, lack of proper storage, and a weak marketing sector. India ranks 103 out of 119 countries on the Global Hunger Index (GHI). This wastage of food products has a huge impact on the lives of the general public (the consumers) and the producers. The solution to this problem is an android application with an interface that allows the producers to register themselves, post details of their product (i.e the quantity, contact details and the location). A separate interface for the transport service providers will be given where they provide the details like their service range, the quantity that they can transport and so on. Further, yet another interface for our app would be for the end consumer. Now our application consolidates all the details given and finds the best transport service provider to accommodate the products as per the order placed by the consumer. Our app aims to solve this issue by providing a way for farmers to identify the demand of each product in different regions.

${ }^{1}$ Mrs.D.Thamizhselvi,Dept of IT, Sri Sairam Engineering College, Chennai Email: thamizhselvi.it@sairam.edu.in. 
Instead of letting the food go to waste, the farmers can transport the food to various other marketplaces, rather than just the nearby/local marketplaces [1-4]. Our app helps carry this out by letting the farmers, marketers and consumers communicate with each other. This eliminates the need for brokers and other such middlemen that usually add to unnecessary expenses. The application can support farmers to gain maximum profit .The application can support customers to get a fair price for the products. Efficient access of data from firebase for better data handling. Can solve the problem of getting transport at the right time for a lower fare [5-7].

\section{Literature review}

In 2019, IEEE published a paper 'Crop shop an application to maximize profit for farmers', but the drawback is the app did not give suitable solution for transport. In 2017, Agriculture Economic Research Association published a paper 'Challenge options and strategies for doubling farmers income in west Bengal', drawback the application did not provide a proper justification for supply demand. In 2017, SSDN publishers published 'Doubling farmers income ', the drawback is it didn't provide good marketing solutions. In 2015, IEEE has published 'Virtual fruits market' and the con of the project is it did not give solution for pricing and this project was based only on fruits [8].

\section{Proposed Module}

The major problem prevalent among farmers is the denial of the right profit reaching the farmers. This problem happens mainly due to the reasons such as lack of proper channels for marketing the product and the fear of crops being wasted if they don't find the right buyer at the right time. This problem also leads to the condition where the farmers sell the goods for the lowest price to a person who acts as an intermediate between the actual buyers and the farmers in figure 1. They tend to retail these goods for a much higher price to yield higher profit which actually belongs to the farmers. This also reflects in the higher selling price of those products in the market for the consumers. If the above. The situation is to be stopped. The farmer may not find the proper buyers at the right time and the products may be wasted [9].

\section{Producer Module}

This module is constituted by the interface provided to the farmers to upload and view the product details. The producers can make use of the application to post the details of their agricultural produce prior to the cultivation date in figure 2 . The details being posted consist of the actual description of the product, the time of availability, available quantity and the price quoted by the farmers for their products. The payment interface is used to view and verify the payments made to the farmers through the application. The producers can also avail transport facilities to deliver the products to the consumer. 


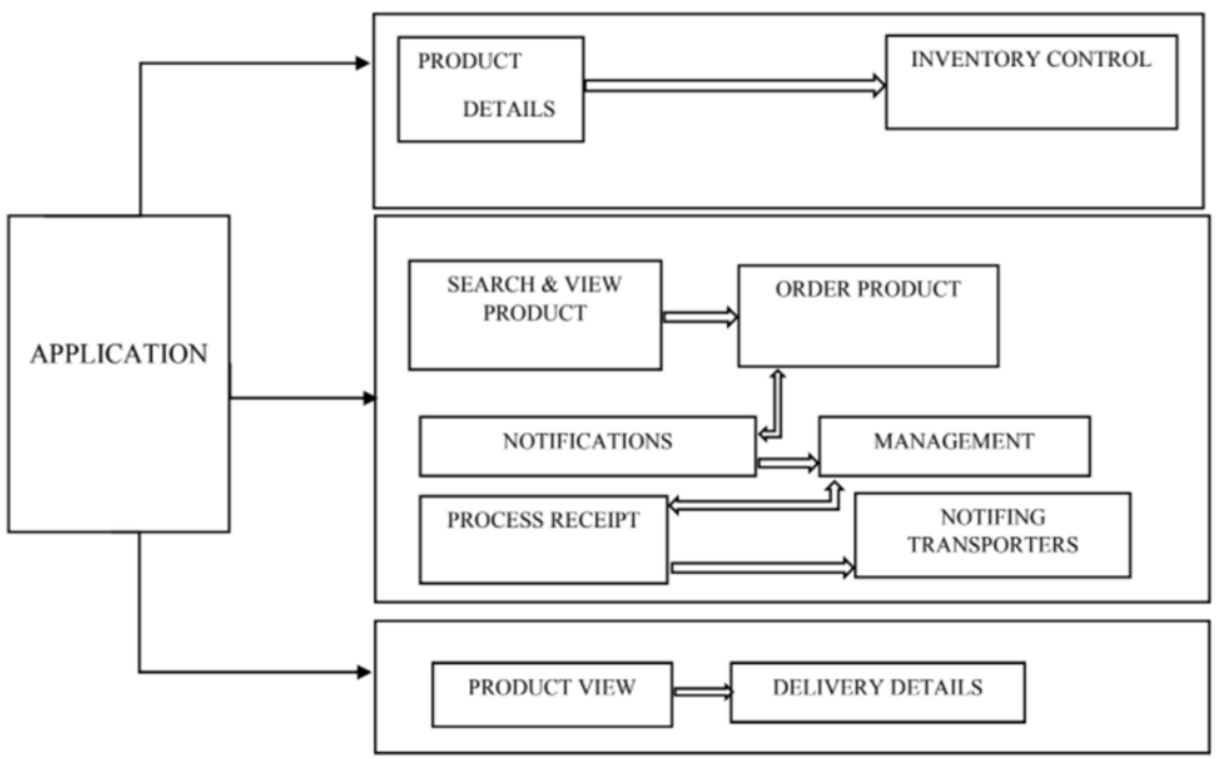

Figure 1. System architecture of the application

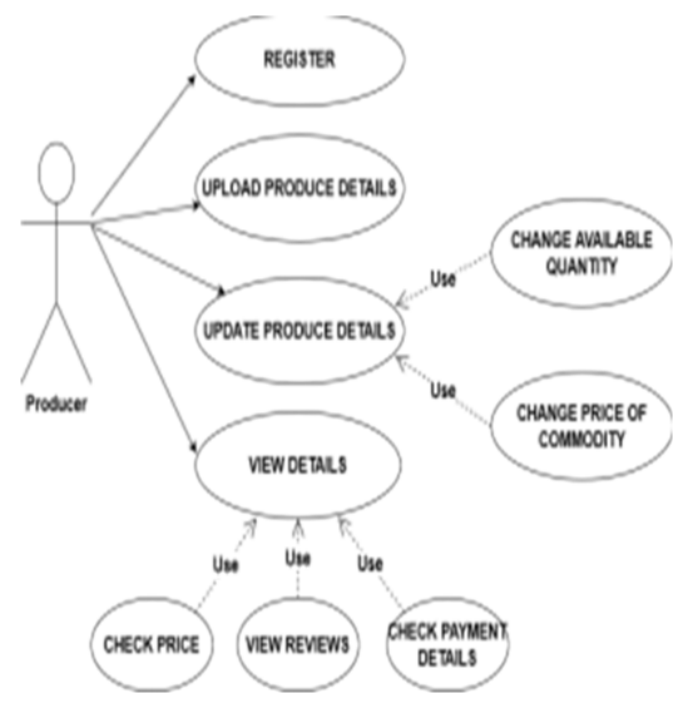

Figure 2. Use Case diagram of Producer module

\section{Customer Module}

The consumer module helps the consumers to buy the agricultural products online directly from the farmers. The consumers can view various products posted in the application and also find the required products for their consumption. Consumers can also view the location details of the product The products can also be viewed based on 
the user requirements. The payment interface in the consumer module helps to make payment directly to the producers to ensure the profit being directly gained by the producers. Figure 3 Consumers are also capable of availing transport through the application that helps them to deliver the products to the required location.

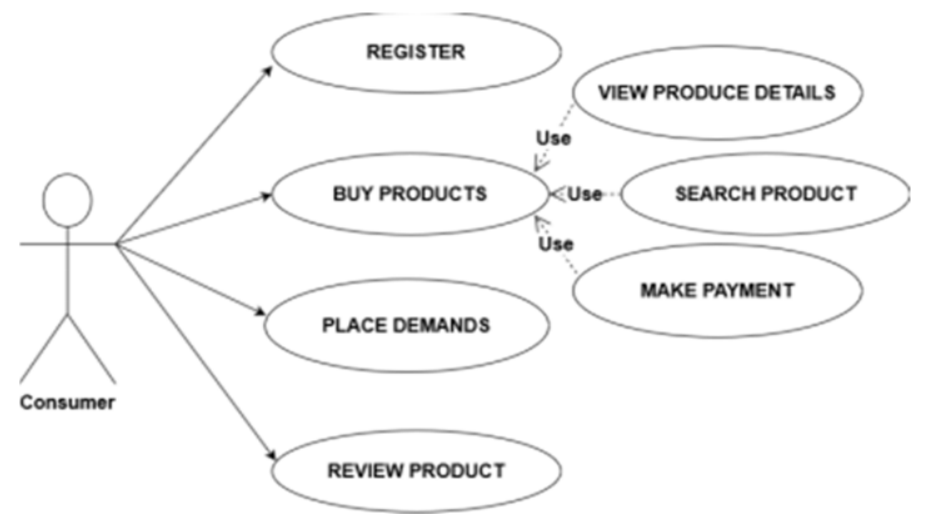

Figure 3. Use case diagram of consumer module

\section{Result and Discussion}

Android Studio, Java programming language, Firebase are the software requirements The mobile application has been developed to bring out the smart farming technologies that enable the farmers to increase profit. First the cultivators should login into the application by giving the basic information. The harvesters/cultivators who are going to harvest their crops in the near future, such as 2 or 3 days in advance, can provide their product details. They can enter the details such as the approximate amount of products that can be produced, estimated cost of those products and the location of those products. Based on their location the users, cultivators, marketing dealers can choose the logistics services. Farm era currently does not have price prediction and proper price exchange, while strategies are still being explored; we are currently focusing on the user base. And by further analysis and data collected from the app can improve its facilities.

\section{Conclusion}

The goal of our project is to sell the farmed products easily and give some sustainable profit to the farmers and to give the good product satisfaction to the consumers. We are in the early stages of the research and we focused on a particular group of people. And the research will continue with a quantitative study .By this we can see better marketing and also understand and predict post consumption behaviours. In summary, we need to expand the scope for this research in order to test the reliability of the results. 


\section{References}

[1] Gunasekara, A; Patel, C. and Tirtiroglou, E. (2001) 'Performance Measures and metrics in Supply Chain Environment'

[2] Haan, J.D.; Groot, D.G.; Loo, E. and Ypenberg M. (2003), 'Flows of Goods or Supply Chains: Lesson from Natural Rubber Industry from Kerala, India'

[3] Jha, S. and Srinivasan, P.W. (1999), 'Grain Price Stabilisation in India: Evaluation of Policy Alternatives'

[4] Joshi, P.K., Gulati A, and Cummings Jr R. (2007). 'Agricultural Diversification and Smallholders in South Asia'

[5] Khan, K.B. and Mentzer, J.T. (1998). 'Marketing's integration with other departments'

[6] Kumar P. (2002). 'Agricultural Performance and Productivity. Indian Agricultural Policy at the crossroads'

[7] Bertolini, R. 'Making Information and Communication Technologies Work for Food Security in Africa- 2020' 